\title{
Insights into the role of fire geometry and violent pyroconvection
}

\author{
$\underline{\text { R. L. Badlan }}^{\mathrm{a}}{ }_{\odot}$ and J. J. Sharples ${ }^{\mathrm{a}}$ and J. P. Evans ${ }^{\mathrm{b}}$ and R. H. D. McRae ${ }^{\mathrm{c}}$

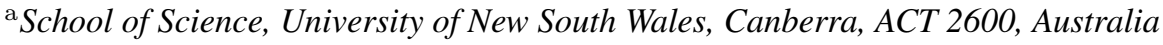 \\ ${ }^{\mathrm{b}}$ Climate Change Research Centre, University of New South Wales, Kensington, NSW 2052, Australia \\ ${ }^{\mathrm{c}}$ Australian Capital Territory Emergency Services Agency, Canberra, ACT 2601, Australia \\ Email: r.badlan@adfa.edu.au
}

\begin{abstract}
Violent fire-driven convection can manifest as towering pyrocumulus (pyroCu) or pyrocumulonimbus (pyroCb) clouds. These events, which can have devastating impacts on the environment and society, appear to be a worsening problem. The main concern is that their associated fire spread is erratic, unpredictable and not generally suppressible. Research into large pyroconvective events has mainly focused on the atmospheric processes involved in normal atmospheric convection, or on surface fire weather and associated fuel conditions. There has been comparatively less attention paid to the role of the fire itself in these coupled fire-atmosphere events.
\end{abstract}

This paper draws upon recent insights into dynamic fire propagation and extreme wildfire development to investigate how the condition of the fire influences the occurrence of violent pyroconvective events. Specifically, the Weather Research and Forecasting Model (WRF) is used to examine how the fire geometry may affect the likelihood of pyroCb occurrence. WRF simulations are used to quantify the role of the spatial expanse, intensity of a wildfire and the presence of wind, in the development of large pyroconvective plumes. The initial work presented here utilises a static heat source of variable dimension and intensity.

The analyses indicate that the shape and intensity of large fires are critical factors driving the development of pyroconvective plumes. These findings provide motivation for further investigation into the effect of the fire's attributes on the immediate atmosphere, and have the potential to improve forecasting of blow up fire events.

Keywords: Wildfire modelling, fire-atmosphere interaction, deep flaming, pyroconvection, pyrocumulonimbus 
R. L. Badlan, J. J. Sharples, et al. Insights into the role of fire geometry...

\section{INTRODUCTION}

Bushfires cost the Australian economy about $\$ 330$ million on average each year, but a single extreme bushfire event can cost an order of magnitude more; for example Black Saturday resulted in the loss of 173 lives and a cost of $\$ 4.4$ billion (Teague et al., 2010). Therefore, understanding the drivers of extreme bushfire development is an important research problem. As bushfires develop, small fires may coalesce into larger fires, which may exhibit sustained and intense flaming over a large spatial expanse ('deep flaming'). Thus, deep flaming describes large areas of the landscape that are affected by quasi-simultaneous active flaming, resulting in large spatial integrals of instantaneous energy release, and should be considered as distinct from more typical frontal wildfire propagation. Triggers for deep flaming may include:

- very strong winds;

- change in wind direction;

- inappropriate use of incendiaries;

- eruptive fire behaviour - steep slopes can cause a fire to accelerate rapidly and intensify (Viegas et al. 2012);

- vorticity-driven lateral spread - strong winds and steep terrain interact to rapidly drive a fire laterally, accompanied by downwind spotting (Simpson et al. , 2013); and

- mass spotting and fire coalescence (Hilton et al., 2017).

The last three triggers are examples of dynamic fire behaviour, which involves abrupt changes in the fire spread without significant changes in ambient conditions. This behaviour arises due to complex interactions between fire, wind and terrain.

Deep flaming has also been implicated as a precursor for violent pyroconvective events, as demonstrated in the 2003 Canberra fires and the 2006 Grose Valley fire in the Blue Mountains west of Sydney (McRae et al., 2015). The development of expansive flaming zones are also suspected to have played a role in the development of the violent pyroconvection associated the 2014 Grampians fire in Victoria and the 'Sir Ivan' fire that destroyed the township of Uarbry, NSW in February 2017. In particular, McRae et al. (2015) demonstrated a spatiotemporal link between spatially expansive, uniform signals in multispectral linescans (interpreted as active flaming), with radar echotop maxima and the strongest radar returns during the 2006 Grose Valley fire. As entrainment of environmental air only occurs along the plume boundary, it is hypothesised that a plume emanating from a larger and more regular-shaped fire area could be subject to less overall entrainment (Lareau and Clements 2017). In particular, the hot and moist air within the plume's core will be more likely to reach the condensation level before it mixes with ambient air and loses its buoyancy. At this level, convection will be further enhanced by latent heat release and atmospheric instability (Finney and McAllister, 2011).

A number of authors have used physical models to investigate the interactions of the atmosphere and a fire (Cunningham and Reeder, 2009; Luderer et al., 2009). While these studies address aspects of the generation of pyroCbs, several questions remain unresolved. In particular, we are not aware of any studies that investigate the role of the geometry of a fire on pyroCb formation, as hypothesised above. A number of related questions pertaining to the effects of fire intensity and the vertical structure of the atmosphere also remain. Therefore, there is a need for further research into how the geometry and spatial expanse of a fire may influence the development of deep pyroconvection. Such research will facilitate better prediction of the most dangerous wildfire events and will improve understanding of fire-atmosphere interactions more generally. Badlan et al. (2017) investigated the conditions surrounding pyroCb formation, by analysing the pyroconvectiive potential produced by circular fires of different sizes fires with varying intensities and atmospheric profiles. This work is continued in this paper.

The prediction of violent pyroconvection is a vital area of research, as its success results in the saving of lives, along with economic consequences. Most research to date has either focussed solely on the surface weather conditions (as an assumed proxy for fire behaviour) or the atmospheric characteristics, such as stability. This work unites both approaches and in particular concentrates on the geometric characteristics of the fire, which have not been a consideration until now. Currently one the main metrics used to evaluate the fire's pyroconvective potential is the total energy release, also called fire power (FP), however, this work seeks to refine this sole input and determine whether the geometry of the heat source also has an effect. To investigate this a series of model simulations are run, which are described in Section 2. Section 3 briefly discusses the main findings and Section 4 contains some final remarks and practical implications of our findings. 
R. L. Badlan, J. J. Sharples, et al. Insights into the role of fire geometry...

\section{METHOD}

The numerical simulations were performed using version 3.9 of the Weather Research and Forecasting model (WRF) - Advanced Research core (ARW) version 3.9 (Skamarock et al., 2008). This is coupled to the WRFFire module and is run in large-eddy simulation (LES) mode (Moeng et al., 2007). This configuration explicitly resolves the atmospheric large-scale eddies whereas the small-scale (subgrid) eddies are modelled using a subfilter-scale stress model. The WRF model is fully compressible and utilises a mass-based terrain-following coordinate system. Although two-way coupling is turned on, the fact that the heat source is not allowed to vary (it is static), means that the coupling is actually just one-way.

The computational domain extends $21 \mathrm{~km}$ in both directions horizontally and $30 \mathrm{~km}$ vertically, with horizontal resolution of $150 \mathrm{~m}$ and a vertically stretched grid with 201 levels. The WRF-Fire model grid is set to a 4:1 resolution of the atmospheric model grid and therefore the fire model is run with $37.5 \mathrm{~m}$ horizontal resolution. The effects of subgrid turbulence are parameterised using a predictive 1.5-order turbulence kinetic energy closure. A Rayleigh damping layer is used in the top $5 \mathrm{~km}$ of the model domain. The simulations are idealised and have no radiation, planetary boundary layer, or cumulus parameterisation schemes (the resolution of the atmospheric grid means that the clouds are explicitly resolved by the model). The microphysics scheme employed is the Single Moment 6-class (WSM6) scheme (Hong and Lim, 2006), and is particularly suitable for high resolution simulations. There is no terrain in the model. The timestep is $0.3 \mathrm{~s}$, the lateral boundaries are open, and the simulation runs for 2 hours and 30 minutes, (the first 20 minutes used for spinup, and the heat fluxes increased linearly over ten minutes).

To quantify the shape of the various geometric configurations, the isoperimetric ratio (IPR) is used, defined as:

$$
I P R=\frac{L^{2}}{A}
$$

where $L$ is the length of the perimeter and $A$ is the area of the heat source (fire). In the first part of this study we only consider convex fire shapes, so that more elongated fire shapes (resembling fire lines) have larger IPR values. The second part introduces the role of annular fires.

Six different-shaped heat sources are analysed (Fig. 1) for each fire intensity of 25,50 , and $100 \mathrm{~kW} \mathrm{~m}^{-2}$.
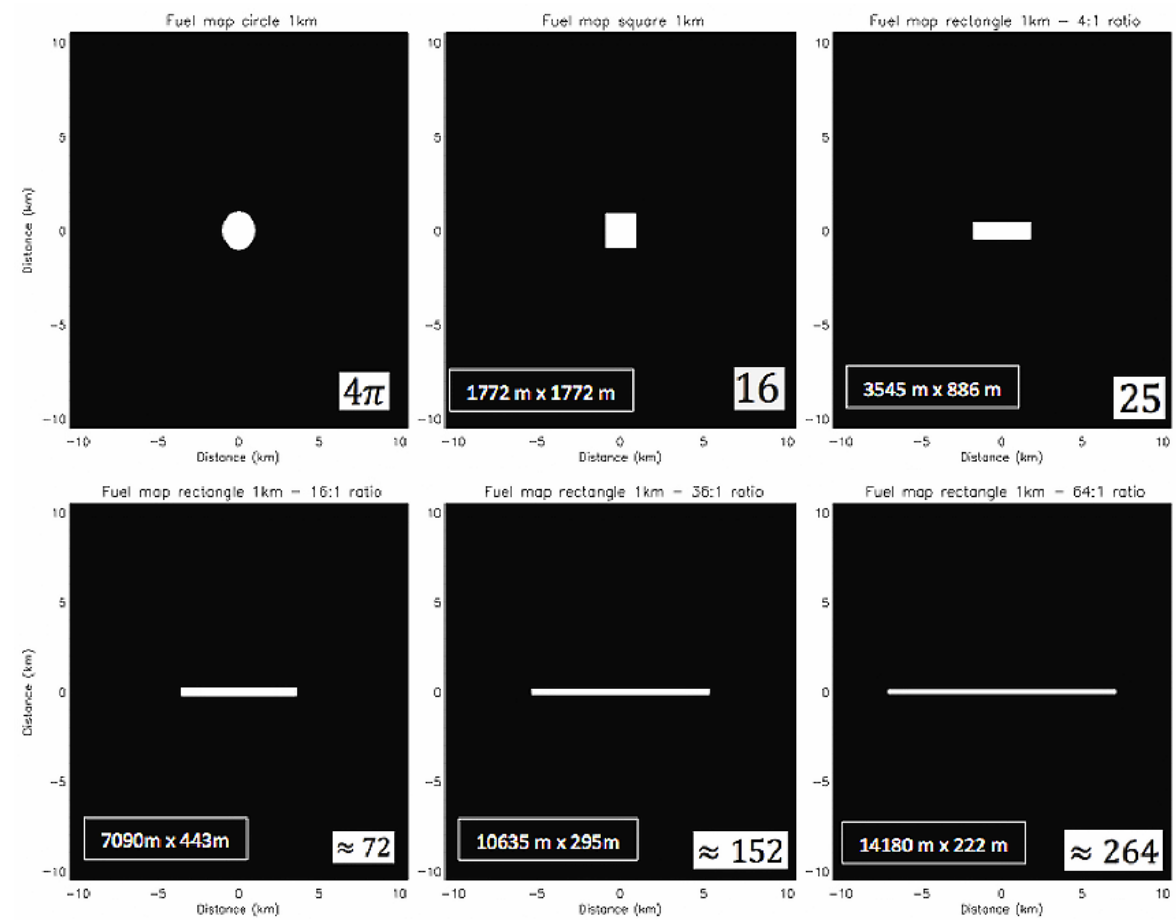

Figure 1. Shape of the heat source for each model run (shown in white). The number in the bottom right of each plot is the IPR, the dimensions are on the bottom left. The circular fire has a radius of $1 \mathrm{~km}$. 
R. L. Badlan, J. J. Sharples, et al. Insights into the role of fire geometry...

The initial wind profile was modified to produce constant vertical shear near the surface such that

$$
U_{0}(z)= \begin{cases}U_{0} & z>h \\ \frac{U_{0} z}{h}, & z \leq h\end{cases}
$$

where $U_{0}$ is $0,1,2,3,4,5,6,7,8,9$, and $10 \mathrm{~m} \mathrm{~s}^{-1}$ in the x-direction (from left to right) and $h=3.0 \mathrm{~km}$ (height of the mixed layer). For the simulations with wind, the domain was extended to $42 \mathrm{~km}$ (in the $x$-direction) by $21 \mathrm{~km}$ (in the $y$-direction).

A number of simulations using annular fires were also run each with the same FP (314 GW). Figure 2 shows heat source configurations of various annular fires (with $360^{\circ}, 270^{\circ}, 180^{\circ}, 135^{\circ}$ and $90^{\circ}$ closure, each with a $50,100,250$ and $500 \mathrm{~m}$ width annulus). The intention is to determine whether there exists any relationship between the fire geometry of both the regular shaped and annular fires, and the height attained by the pyroconvective plume. The IPR for the $360^{\circ}$ cases was calculated by treating these fires as a solid circle (i.e. the IPR equals $4 \pi$ ) and as an annulus; for all the other simulations, the actual perimeter is calculated.
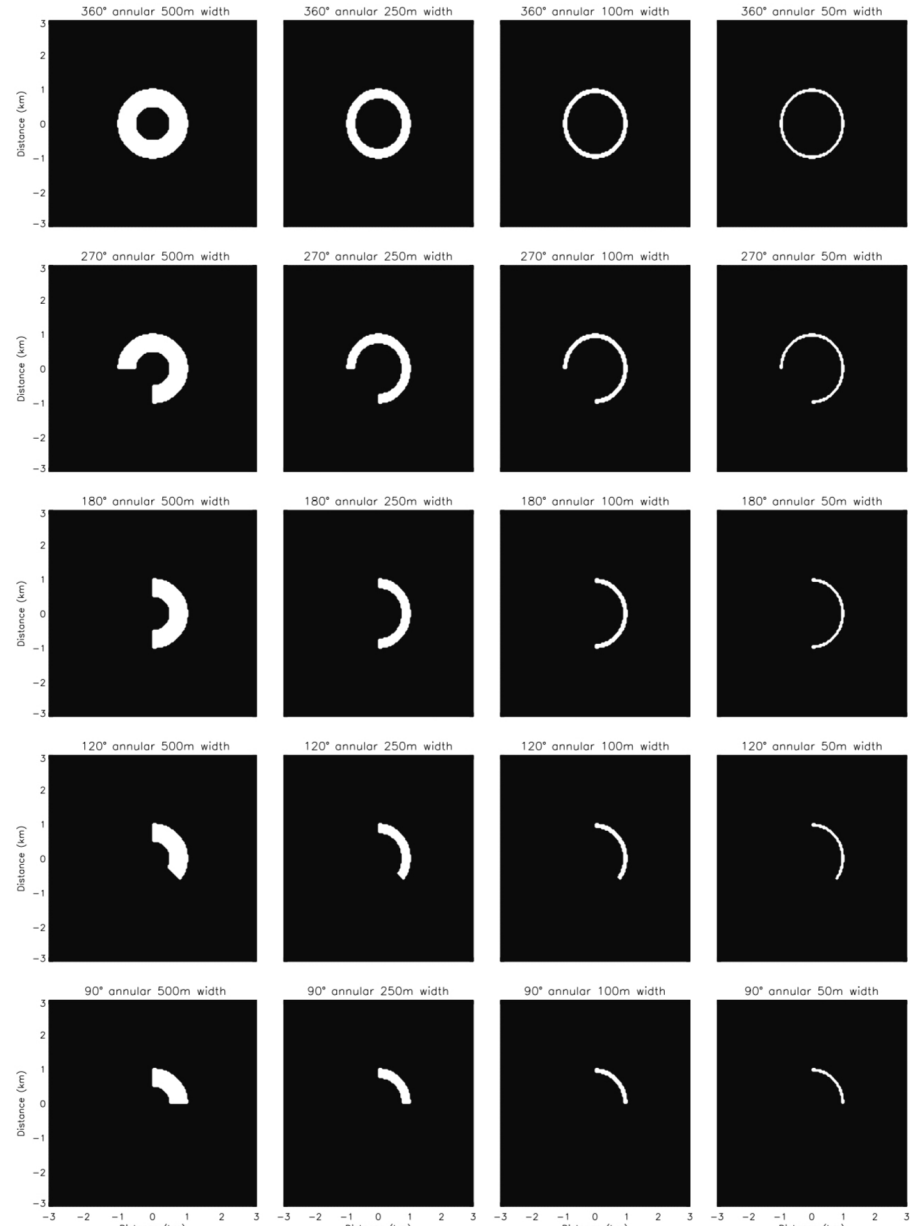

Figure 2. Fuel maps for all the annular fire runs (white indicates heat source. Fires have $1 \mathrm{~km}$ radius and a total energy release equivalent to the $1 \mathrm{~km}$ circular fire. 
R. L. Badlan, J. J. Sharples, et al. Insights into the role of fire geometry...

\section{RESULTS}

\subsection{IPR}

The relationship between the $\log (\mathrm{IPR})$ and the maximum plume height shows there is a correlation between the shape of the fire $(\log (\mathrm{IPR}))$ for the $100 \mathrm{~kW} \mathrm{~m}^{-2}$ simulations (Fig. 3). As a fire transitions from a regular areal shape (e.g. deep-flaming) to a linear shape (e.g. fireline), the IPR increases and the maximum plume height diminishes, due to greater entrainment as the perimeter to area ratio increases. The increased entrainment means that the plume is diluted and loses buoyancy.

\section{Dry model runs}

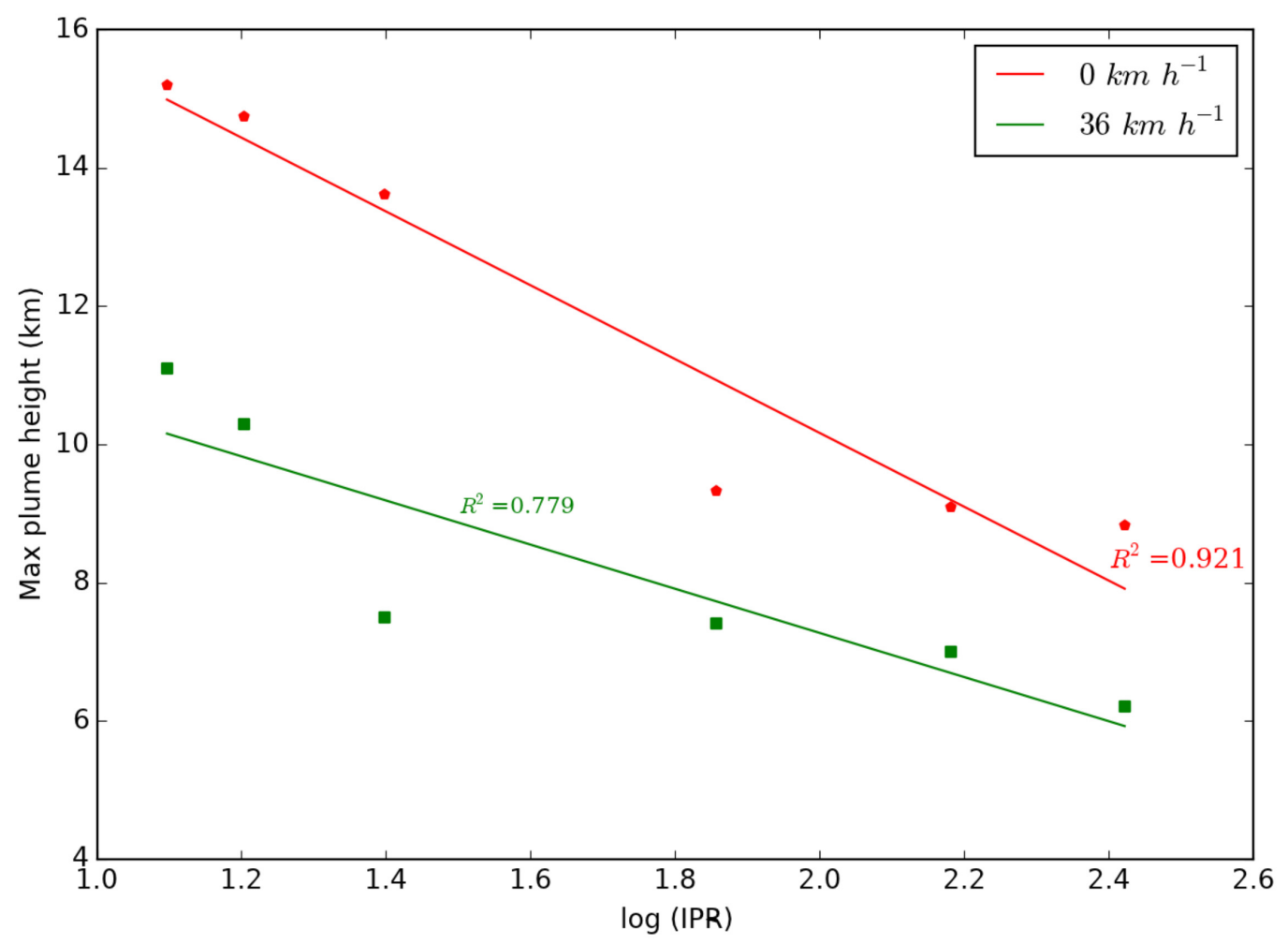

Figure 3. Relationship between $\log (\mathrm{IPR})$ and maximum plume height $(\mathrm{km})$ for $100 \mathrm{~kW} \mathrm{~m}^{-2}$ with no wind, and $10 \mathrm{~m} \mathrm{~s}^{-1}\left(36 \mathrm{~km} \mathrm{~h}^{-1}\right)$.

This relationship is also maintained with the introduction of wind into the simulation, although for extremely strong wind $\left(\sim 36 \mathrm{~km} \mathrm{~h}^{-1}\right)$, this relationship weakens slightly. Obviously, as the magnitude of the wind increases, the plume tilts over (downwind) which results in a lowering of the plume height with increasing wind strength. However, the shape of the fire is still influential, with deep flaming fires producing higher plumes.

\subsection{Annular Fires}

The annular fires also show a relationship between the IPR and the plume height. The IPR for $360^{\circ}$ fires were calculated in two ways: firstly treating the shape as an annulus (adding both the interior and exterior fire boundaries which produced a weak correlation with plume height) (Fig. 4 (red line)) and secondly, calculating the IPR as a solid circle by using just the outer boundary (the width of the annulus does not affect the plume height)(Fig. 4 (black line)). 
R. L. Badlan, J. J. Sharples, et al. Insights into the role of fire geometry...

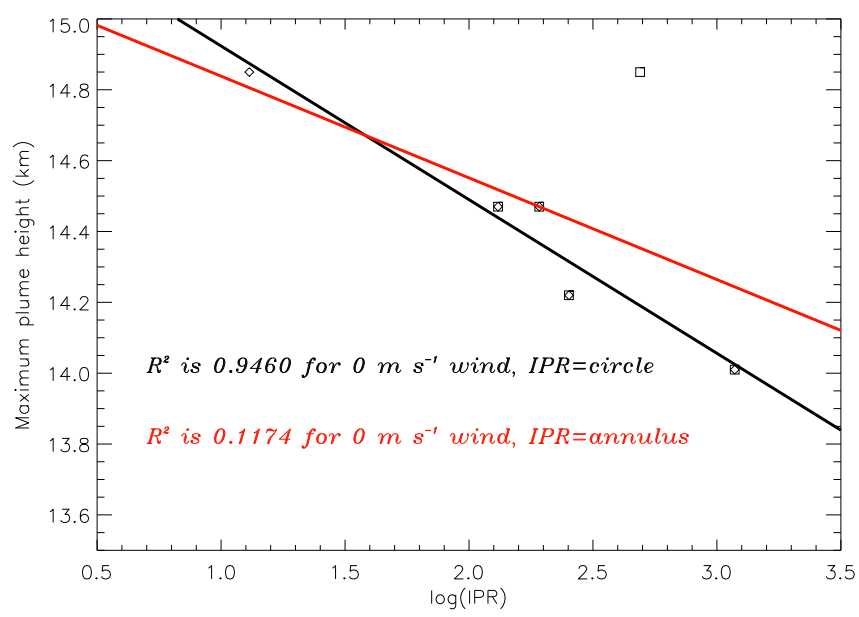

Figure 4. Relationship between $\log (\mathrm{IPR})$ and maximum plume height $(\mathrm{km})$ for the $360^{\circ}, 270^{\circ}, 180^{\circ} 135^{\circ}$, and $90^{\circ}$ annulus fires with a $50 \mathrm{~m}$ width and $1 \mathrm{~km}$ radius. Two correlations are shown: the black line shows the case where the IPR is calculated using the $360^{\circ}$ case as a circle and the red line represents the IPR calculated as an annulus.

Figure 5 (left) shows the strong convergence for fully enclosed fires, which explains why the width of the annulus does not affect plume height, and why the IPR for the $360^{\circ}$ fires is best represented by only considering the external perimeter of the fire. The surface winds converge towards the centre of the fire and so the $360^{\circ}$ cases are best treated as regular circular fires. However once the annulus is broken for $90^{\circ}-270^{\circ}$ annular fires (Fig. 5 (right)), the convergence decreases, the surface winds enter the circle and act on both sides of the annulus - the fires act as a linear fire or fireline. However, as the fireline is curved, the effective perimeter is smaller that the actual.
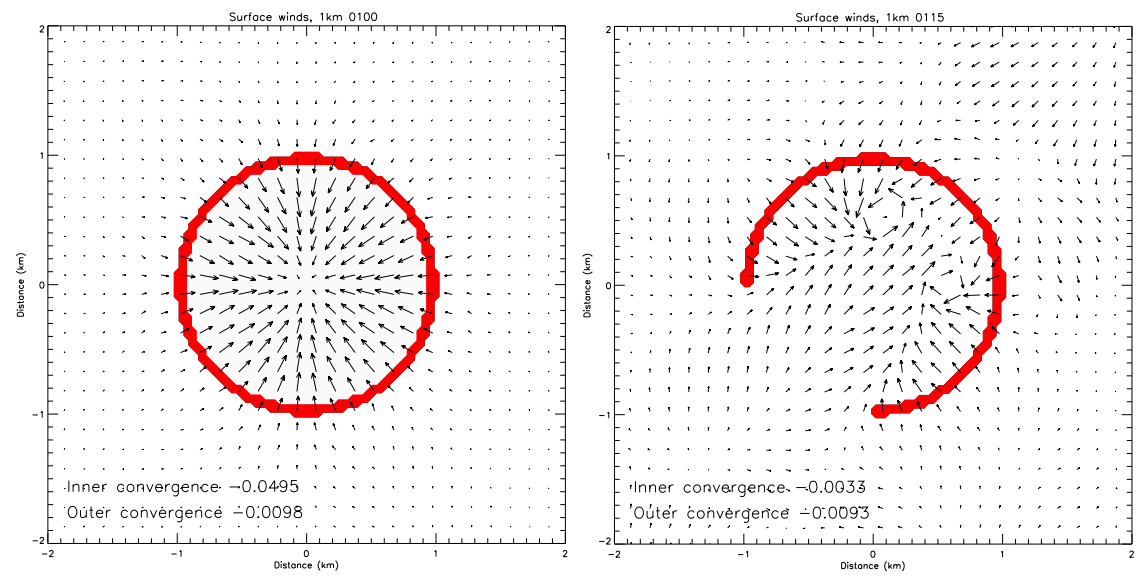

Figure 5. Fire area (shown in red) and surface wind $(10 \mathrm{~m})$ vectors for $360^{\circ}$ and $270^{\circ}$ closure with $50 \mathrm{~m}$ depth annulus and a radius of $1 \mathrm{~km}$.

\section{CONCLUSIONS}

Current approaches to evaluating pyroconvective potential focus on indices relating to atmospheric instability and moisture, or equivalent measures of fire power. This work finds that the magnitude of fire power on its own is not sufficient for determining the pyroconvective potential of a wildfire. Indeed, our results indicate that the spatial configuration of fire power, described here by the IPR, is a critical factor in driving deep pyroconvection, and hence whether a fire will develop towering pyroCu or pyroCb. 
R. L. Badlan, J. J. Sharples, et al. Insights into the role of fire geometry...

Entrainment of ambient air into the plume causes dilution which inhibits buoyancy. Therefore the greater the perimeter-to area ratio, the greater the IPR, the greater the entrainment and the weaker the plume. Deep flaming is more likely to produce undiluted, protected cores enabling deeper vertical coupling into the troposphere and producing taller plume heights.

This research provides theoretical support for the 'Blow-Up Fire Outlook' (BUFO) model (McRae and Sharples, 2014) that has been trialled in NSW and the ACT. Anticipating the occurrence of dynamic fire propagation and its likely effect on the spatial expanse and geometry of the fire, can further inform prediction of violent pyroconvective events. The use of both the fire power and IPR-to-plume height relationship may be informative in diagnosing fires which are likely to blow-up and produce extreme fires. The research also has implications for land management e.g. maintaining ecological corridors whilst reducing fuel load, may aid in reducing violent pyroconvection, and also enable early evacuation of fire crews and residents.

\section{ACKNOWLEDGEMENT}

This research was funded under the Australian Research Council's Discovery Indigenous Scheme (IN160100029), and undertaken with the assistance of resources provided by the NCI National Facility at the Australian National University through the National Computational Merit Allocation Scheme supported by the Australian Government. The authors are grateful to Michael Reeder, Todd Lane and Janice Coen for helpful discussions. Thanks also to Chris Thomas for sharing his modifications to the WRF code and for general advice.

\section{REFERENCES}

Badlan, R., J. Sharples, J. Evans, and R. McRae (2017). The role of deep flaming in violent pyroconvection. In MODSIM2017, 22nd International Congress on Modelling and Simulation, pp. 1090-1096. Modelling and Simulation Society of Australia and New Zealand Hobart, Australia.

Cunningham, P. and M. J. Reeder (2009). Severe convective storms initiated by intense wildfires: Numerical simulations of pyro-convection and pyro-tornadogenesis. Geophysical Research Letters 36(12).

Finney, M. A. and S. S. McAllister (2011). A review of fire interactions and mass fires. Journal of Combustion 2011, 14 pages.

Hilton, J., J. Sharples, A. Sullivan, and W. Swedosh (2017). Simulation of spot fire coalescence with dynamic feedback. In MODSIM2017, 22nd International Congress on Modelling and Simulation, pp. 1111-1117. Modelling and Simulation Society of Australia and New Zealand Hobart, Australia.

Hong, S.-Y. and J.-O. J. Lim (2006). The WRF single-moment 6-class microphysics scheme (WSM6). AsiaPacific Journal of Atmospheric Sciences 42(2), 129-151.

Lareau, N. P. and C. B. Clements (2017). The mean and turbulent properties of a wildfire convective plume. Journal of Applied Meteorology and Climatology 56(8), 2289-2299.

Luderer, G., J. Trentmann, and M. O. Andreae (2009). A new look at the role of fire-released moisture on the dynamics of atmospheric pyro-convection. International Journal of Wildland Fire 18, 554-562.

McRae, R. and J. Sharples (2014). Forecasting conditions conducive to blow-up fire events. CAWCR Res Lett 11, 14-19.

McRae, R., J. Sharples, and M. Fromm (2015). Linking local wildfire dynamics to pyrocb development. Natural Hazards and Earth System Sciences 15(3), 417.

Moeng, C., J. Dudhia, J. Klemp, and P. Sullivan (2007). Examining two-way grid nesting for large eddy simulation of the pbl using the wrf model. Monthly weather review 135(6), 2295-2311.

Simpson, C. C., J. J. Sharples, J. P. Evans, and M. F. McCabe (2013). Large eddy simulation of atypical wildland fire spread on leeward slopes. International Journal of Wildland Fire 22(5), 599-614.

Skamarock, W. C., J. B. Klemp, J. Dudhia, D. O. Gill, D. M. Barker, M. Duda, X.-y. Huang, W. Wang, and J. G. Powers (2008). A description of the Advanced Research WRF version 3. Technical report, National Center For Atmospheric Research Boulder Co Mesoscale and Microscale Meteorology Div.

Teague, B., R. McLeod, and S. Pascoe (2010). Final report, 2009 Victorian bushfires royal commission. Technical report, Parliament of Victoria, Melbourne, Victoria, Australia.

Viegas, D. X., J. R. Raposo, D. A. Davim, and C. G. Rossa (2012). Study of the jump fire produced by the interaction of two oblique fire fronts. Part 1: Analytical model and validation with no-slope laboratory experiments. International Journal of Wildland Fire 21(7), 843-856. 